\title{
Typical MRI findings of bilateral ischial bursitis: bilateral Weaver's bottom
}

\author{
Rajaram Sharma (D) , ${ }^{1,2}$ Tapendra Tiwari, ${ }^{1}$ Saurabh Goyal ${ }^{1}$
}

${ }^{1}$ Department of Radiodiagnosis, Pacific Institute of Medical Sciences Umarda Campus, Udaipur, India

${ }^{2}$ Department of Radiodiagnosis, Seth GS Medical College and KEM Hospital, Mumbai, India

\section{Correspondence to}

Dr Rajaram Sharma;

hemantgalaria13@gmail.com

Accepted 28 September 2021

\section{DESCRIPTION}

Weaver's bottom, popularly known as ischial bursitis, is a highly unusual entity affecting adults and older populations. Ischial bursitis is an inflammation of the ischial bursa and fluid collection and associated changes in the hamstring muscle complex (HMC). The ischial bursa lies near the ischial tuberosity, protected by the gluteus maximus muscle during extension; however, this protective covering is lost during sitting position and is sandwiched between the ischial tuberosity and external surface. The ischial tuberosity is an important landmark that provides attachment to the HMC. The HMC comprises of biceps femoris, semitendinosus and semimembranosus. ${ }^{1}$ The HMC is the active extensor of the pelvis and flexor of the knee, making it highly prone to sprain and injuries as it involves various complex movements across the hip and knee joints. Diagnosis in early stage and prompt treatment can prevent further damage and tears of HMC. The diagnosis of ischial bursitis is often missed due to its rarity and non-specific symptoms. The symptoms include pain in the buttock, posterior thigh, perineum, difficulty getting up and local swelling. The diagnosis is usually made clinically; however, ultrasound or MRI is advisable for confirmation. ${ }^{2}$ The MRI is the ideal imaging modality to confirm the diagnosis and to exclude the differentials. The MRI scan typically shows fluid-filled distended bursa with additional abnormalities in the HMC. The treatment for this entity includes analgesics, cold therapy, rest, fractional massage and therapeutic stretch exercises.

A 55 -year-old woman presented with pain in bilateral gluteal regions for the last 6 months. Pain aggravated over the previous 2 months. She complained of difficulty in changing position from sitting to standing and vice versa. Vital parameters

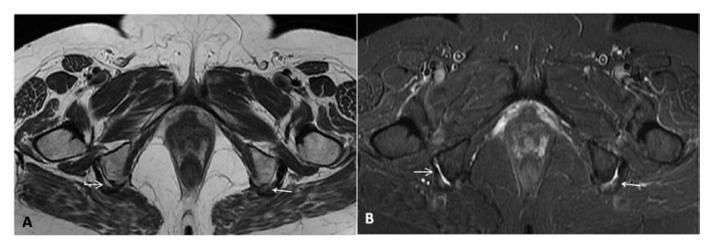

(C) BMJ Publishing Group Limited 2021. No commercial re-use. See rights and permissions. Published by BMJ.

To cite: Sharma R,
Tiwari T, Goyal S. BMJ Case
Rep 2021;14:e246665.
doi:10.1136/bcr-2021-
246665

Figure 1 Unenhanced MRI images of the pelvis in the axial plane. T2 weighted image (A) and short tau inversion recovery weighted image (B) demonstrate a band of free fluid in the bilateral ischial bursae along with thickening and loss of hypointense signals of the tendons at the origin of hamstring muscle complex representing chronic microtears (white arrow).

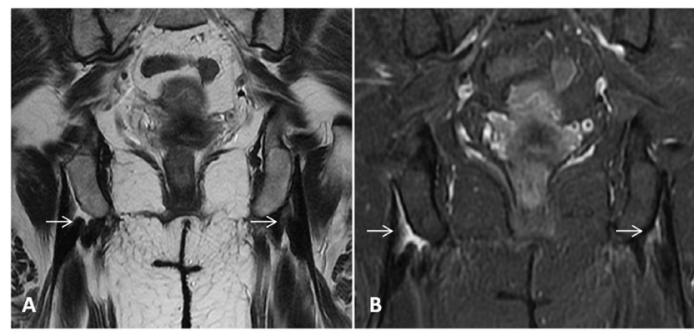

Figure 2 Unenhanced MRI coronal images of the pelvis. T2-weighted image (A) and short tau inversion recovery weighted image (B) depict tendon fraying and fluid signal intensity at the HMC origin. The abnormal hyperintense signals are extending along the HMC tendons suggest repetitive tear with enthesopathy (white arrow). HMC, hamstring muscle complex.

were normal at the time of presentation. On local examination, there was tenderness over bilateral gluteal regions. The active flexion movements at the knee were restricted. She was advised for radiographs of bilateral hip and sacroiliac joints, which were unremarkable. For further evaluation, she underwent MRI of bilateral hip joints, including the pelvis. The MRI revealed abnormal increased fluid intensity signals in ischial bursae on both sides and loss of normal hypointense signals in the tendons of hamstring muscles (figure 1A,B). The tendons had wavy contours with increased fluid signal intensities representing chronic microtears (figures 2A, B and 3). The final diagnosis of ischial

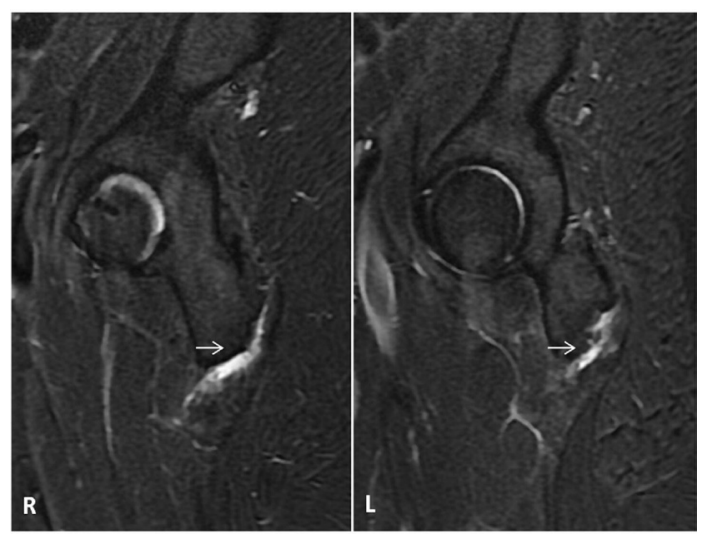

Figure 3 Non-enhanced MRI sagittal images of the pelvis. Short tau inversion recovery images of right (R) and left ( $\mathrm{L}$ ) ischial tuberosities demonstrate hyperintense signal with a band of fluid collection at bursae. Fluid is seen extending along the thickened hamstring muscle complex tendons represent bursitis with enthesopathy (white arrow). 


\section{Patient's perspective}

I was pretty uncomfortable sitting on the table or the floor routinely, hampering my routine life. The doctor advised me to get the MRI for confirmation of the diagnosis. I was told that I had some inflammatory condition of the hip bone, so-called ischial bursitis. I was advised to take painkillers along with physiotherapy. My symptoms are now very much reduced.

\section{Learning points}

- Ischial bursa is very important as it is linked with pathologies of hamstring muscle complex (HMC).

- Early diagnosis and treatment is a must in the pathologies of ischial bursa and HMC to prevent irreversible damage.

- MRI of the pelvis is the modality of choice for diagnosing diseases of ischial bursa and HMC. bursitis with chronic HMC tendinopathy was made and she was prescribed physiotherapy and analgesics for her ailments.

She has been kept on the follow-up with our hospital and she was recovering in a usual way till the last follow-up.

Contributors RS and TT contributed to the planning, design, conception, data acquisition and data interpretation. SG contributed to data acquisition and data interpretation.

Funding The authors have not declared a specific grant for this research from any funding agency in the public, commercial or not-for-profit sectors.

Competing interests None declared.

Patient consent for publication Consent obtained directly from patient(s). Provenance and peer review Not commissioned; externally peer reviewed.

\section{ORCID iD}

Rajaram Sharma http://orcid.org/0000-0003-1126-5875

\section{REFERENCES}

1 Koulouris G, Connell D. Hamstring muscle complex: an imaging review. Radiographics 2005;25:571-86

2 Cho K-H, Lee SM, Lee YH, et al. Non-infectious ischiogluteal bursitis: MRI findings. Korean J Radiol 2004;5:280-6.

Copyright 2021 BMJ Publishing Group. All rights reserved. For permission to reuse any of this content visit

https://www.bmj.com/company/products-services/rights-and-licensing/permissions/

BMJ Case Report Fellows may re-use this article for personal use and teaching without any further permission.

Become a Fellow of BMJ Case Reports today and you can:

- Submit as many cases as you like

- Enjoy fast sympathetic peer review and rapid publication of accepted articles

- Access all the published articles

Re-use any of the published material for personal use and teaching without further permission

\section{Customer Service}

If you have any further queries about your subscription, please contact our customer services team on +44 (0) 2071111105 or via email at support@bmj.com. Visit casereports.bmj.com for more articles like this and to become a Fellow 